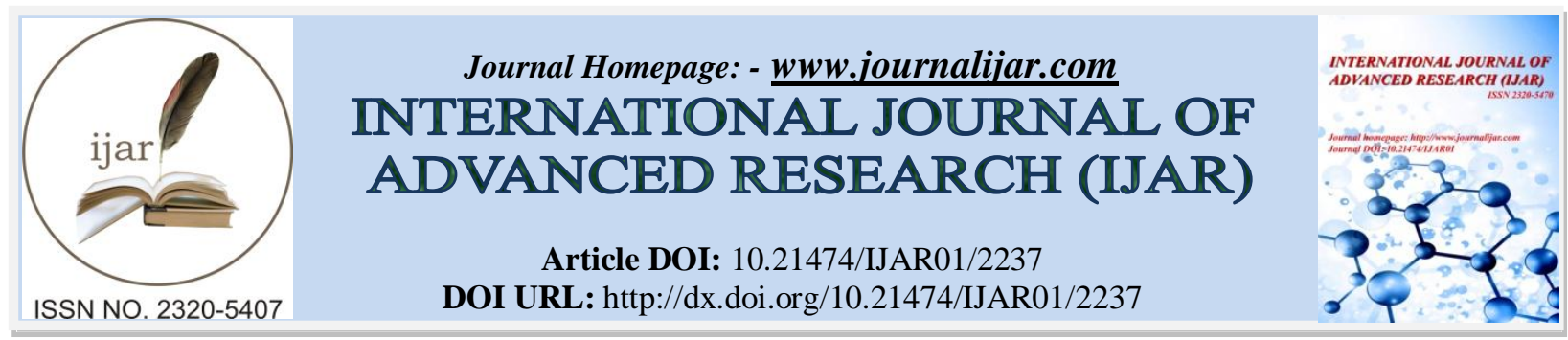

RESEARCH ARTICLE

\title{
NEPHROPROTECTIVE EFFECT OF METHANOLIC EXTRACT OF PETROSLINUM CRISPUMS LEAVES AGAINST RIFAMPIN INDUCED NEPHROTOXICITY IN RATS.
}

\author{
Esraa Ramadan ${ }^{1}$, Tarig. H. A. Bilal ${ }^{1}$, Idris, O. $\mathrm{F}^{2}$ and Samia H. Abdelrahman ${ }^{3}$.
}

1. Department of Biochemistry, School of Medical Laboratories Sharg Alneel college. Khartoum Sudan.

2. Department of Biochemistry, Faculty of Science and technology, Alneelain University, Khartoum, Sudan.

3. Department of Biochemistry, Veterinary Research Institute, Animal Resources Research Corporation. P.O.Box. 8067 Alamarat Khartoum Sudan.

\section{Manuscript Info}

(.........................

Manuscript History

Received: 29 September 2016

Final Accepted: 30 October 2016

Published: November 2016

\section{Abstract}

The study was conducted for the renal protective activity of methanolic extract of, Petroslinum crispum leaves against renal toxicity induced by rifampin injection in rats. This plant is used in traditional medicine for the treatment of renal failure, inflammation of kidney and other disease. The renal toxicity was produced by administration of rifampin at dose rate $70 \mathrm{mg} / \mathrm{kg} \mathrm{I} / \mathrm{p}$ for 28 days. The plant extract was given by simultaneous oral administration of methanolic extract of Petroslinum crispum leaves at a dose rate of 300 and $600 \mathrm{mg} / \mathrm{kg}$ for 28 days. It was found that the induced toxicity was inhibited by decreased level of serum urea, creatinin, sodium (Na) and potassium (K). Histopathological examination revealed protection of the kidney from the marked necrosis of renal tubules that induced by rifampin.

Copy Right, IJAR, 2016,. All rights reserved.

\section{Introduction:-}

The kidneys are a pair of organs located in the back of the abdomen. Each kidney is about 4 or 5 inches long -- about the size of fist.The kidneys' functions are to filter the blood. All the blood in our bodies passes through the kidneys several times a day. The kidneys remove wastes, control the body's fluid balance, and regulate the balance of electrolytes. As the kidneys filter blood, they create urine, which collects in the kidneys' pelvis -- funnel-shaped structures that drain down tubes called ureters to the bladder. Produce rennin, an enzyme that helps regulate blood pressure, Produce erythropoietin, which stimulates red blood cell production and Produce an active form of vitamin D, needed for bone health. Chronic kidney disease (CKD), also known as chronic renal disease, is progressive loss in kidney function over a period of months or years. The symptoms of worsening kidney function are not specific, and might include feeling generally unwell and experiencing a reduced appetite. Often, chronic kidney disease is diagnosed as a result of screening of people known to be at risk of kidney problems, such as those with high blood pressure or diabetes and those with a blood relative with CKD. This disease may also be identified when it leads to one of its recognized complications, such as cardiovascular disease, anemia, pericarditis or renal osteodystrophy (the latter included in the novel term CKD-MBD). ${ }^{[1][2]} \mathrm{CKD}$ is a long-term form of kidney disease; thus, it is differentiated from acute kidney disease (acute kidney injury) in that the reduction in kidney function must be present for over 3 months. CKD is an internationally recognized public health problem affecting 5-10\% of the world

Corresponding Author:- Esraa Ramadan.

Address:- Department of Biochemistry, School of Medical Laboratories Sharg Alneel college. Khartoum Sudan. 
population. ${ }^{[3][4]}$.Nephrotoxicity is poisonous effect of some substances, both toxic chemicals and medication on the kidneys. Many of the drugs causes toxicity to the kidney, these drugs used in chemotherapy such as Cisplatin, Carboplatin, Carmustine and high dose methotrexate biologic therapy such as Interleukin-2 or Interferon Alfa, antibiotics and antimicrobial such as Amphotericin B, Gentamicin, Vancomycin and Rifampin (Rifadin). Currently, medicinal plants are widely used in the treatment of many diseases owing their safety, cheapness and nontoxicity when compared with the synthetic drugs ${ }^{[5]}$. It has been estimated that about $80 \%$ of the world population relies on natural and botanical preparations as medicine to meet their health needs ${ }^{[6]}$. Also, the dietary intake of carotenoids, vitamins and flavonoids, which are widely distributed in plants, could be useful in protecting against drug-induced nephrotoxicity ${ }^{[7]}$.

Tuberculosis (TB), a serious disease caused by Mycobacterium tuberculosis, is a growing international health concern ${ }^{[8]}$. It primarily affects lungs and secondarily smonths course of antibiotics including isoniazid (INH), rifampicin (RIF), pyrazinamide (PZA) and ethambutol or streptomycin ${ }^{[9]}$. The use of isoniazid and its combination with rifampicin is associated with liver damage that could result in acute liver failure with a high mortality rate ${ }^{[10}$, 11]. The rate of their hepatotoxicity is much higher in developing countries compared to that in developed countries, even with using the same dose schedule ${ }^{[12]}$. Although the hepatotoxic effects of the anti-tuberculosis drugs have been extensively studied, their induced nephrotoxicity have been poorly documented. The study of Mahmouds et al ${ }^{[11]}$ demonstrated that oxidative stress is implicated in the INH-induced toxicity in rats. In addition, Lopez-Novoaetal ${ }^{[13]}$ reported that reactive oxygen species (ROS) and oxidative stress represent the central key in the pathogenesis of drug-induced renal damage. Therefore, the use of antioxidants could offer protection against drug-induced renal damage.

Petroslinum crispum seed was used traditionally as a carminative to decrease flatulence and colic pain. The root was used as a diuretic and the juice to treat kidney ailments. Petroslinum crispum oil also has been used to regulate menstrual flow in the treatment of amenorrhea and dysmenorrhea, and is purported to be an abortive. Bruised leaves have been used to treat tumors, insect bites, lice, skin parasites, and contusions. At one time, parsley tea was used to treat dysentery and gallstones. Other traditional uses include treatment of diseases of the prostate, liver, and spleen. Historically, Petroslinum crispum also has been used in the treatment of anemia, arthritis, and cancers, as an expectorant, antimicrobial, aphrodisiac, hypotensive, diuretic, and laxative. It also has been used as a scalp lotion to stimulate hair growth. However, there have been no clinical trials to confirm these uses. ${ }^{[14]}$

\section{Material and method:-}

Animals:-

Twenty rats Wister white (albino) weighting 100-150gm, were obtained from the atomic energy Research institute. They were housed in laboratory cages, maintained in a room under standard environmental condition, controlled temperature (22 $\pm 2 \mathrm{c})$, relative humidity $(60 \%)$ with free access to water and formula rat feed (corn powder, protein). Animals were apparently healthy and there were identified by color tail marks. 10 days was allowed as a preliminary adaptive period.

\section{Plant material:-}

Petroselinum crispum leaves belong to the family of Apiaceae were collected in May 2014 from Alkhartoum city. The plant was authenticated by the botanists in medicinal and aromatic plants research institute.

\section{Preparation of extract:-}

$500 \mathrm{~g}$ of Petroselinum crispum was successively extracted by soaking in $80 \%$ methanol for about seventy two hours of solvent with daily filtration and evaporation. Solvents were evaporated under reduced pressure to dryness using rotary evaporator apparatus.

Experimental design:

Group A: serving as control for 28 days. Group B: was injected by rifampin $\mathrm{I} / \mathrm{p}-0.8 \mathrm{ml} / \mathrm{Kg}$ induced nephrotoxicity for 28 days. Group C: was injected by rifampin $\mathrm{I} / \mathrm{p}-0.8 \mathrm{ml} / \mathrm{Kg}$ and treated with the low dose $(300 \mathrm{mg} / \mathrm{Kg})$ of the 
methanolic extract of Petroselinum crispum leaves. Group D: was injected by rifampin I/p-s $0.8 \mathrm{ml} / \mathrm{Kg}$ and treated with high dose $(600 \mathrm{mg} / \mathrm{Kg})$ of methanolic extract of Petroselinum crispum leaves.

Serum concentration of urea, creatinine, and $\mathrm{K}$ were chemically estimated.

\section{Result and discussion:-}

Kidney injury is a severe complication that can disturb treatment and cause permanent kidney damage. It has been reported that nephropathy is an important microvascular complication of anti-tuberculosis therapy multiple studies have reported that oxidative stress and inflammation are implicated in drug-induced organ toxicity. However, renal injury induced by anti-tuberculosis therapy is usually reversible and could be treated appropriately if detected early. Therefore, the use of antioxidants could protect against RIF-induced oxidative stress and nephrotoxicity. Oral administration of rifampin in dose of $70 \mathrm{mg} / \mathrm{kg} \mathrm{I} / \mathrm{p}$ for 28 days to rats caused nephrotoxicity manifested by significant $(\mathrm{P}<0.05)$ increased in serum level of urea, creatinine, $\mathrm{Na}$ and $\mathrm{K}$ when compared with the (negative) control group. Oral administration of methanolic extract of Petroslinum crispum leaves for 28 days induced significant $(\mathrm{P}<0.05)$ decreases in high serum levels of urea, creatinine, $\mathrm{Na}$ and $\mathrm{k}$ when compared with rifampin intoxicated rats Table (1to 4) and Fig(1 to 4). We designed the current study to test the hypothesis that petroslinum crispum leaves extract could protect against Rifampin( RIF)-induced renal damage in rats through attenuation of inflammation and prevention of oxidative stress.

The present findings showed that the administration of Rifampin (RIF) has induced renal injury and glomerular dysfunction as evident by the elevated serum urea, creatinine,sodium and potassium levels. These parameters are often regarded as reliable markers of renal damage ${ }^{[15]}$. In addition, serum creatinine has been used to estimate glomerular function and its elevation is an indicator of renal failure ${ }^{[16]}$. The elevated serum markers of renal toxicity is agreement with the study of Hashmi et a ${ }^{[17]}$ who reported increased serum levels of urea and creatinine in albino rabbits following administration of anti-tuberculosis drugs Isoniazid (INH) and Rifampin (RIF) induced nephrotoxicity . In the present study, results suggested that methanolic extract of petroslinum crispum $600 \mathrm{mg} / \mathrm{kg}$ significantly reduced Rifampin-induced elevated serum levels of creatinine, urea, sodium, and potassium. The histological findings also supported the nephroprotective action of methanolic extract of petroslinum crispum. It can be concluded from the present study that nephroprotective effect of petroslinum crispum was showed due to the presence of one or more of flavanoids.

Fig (1)

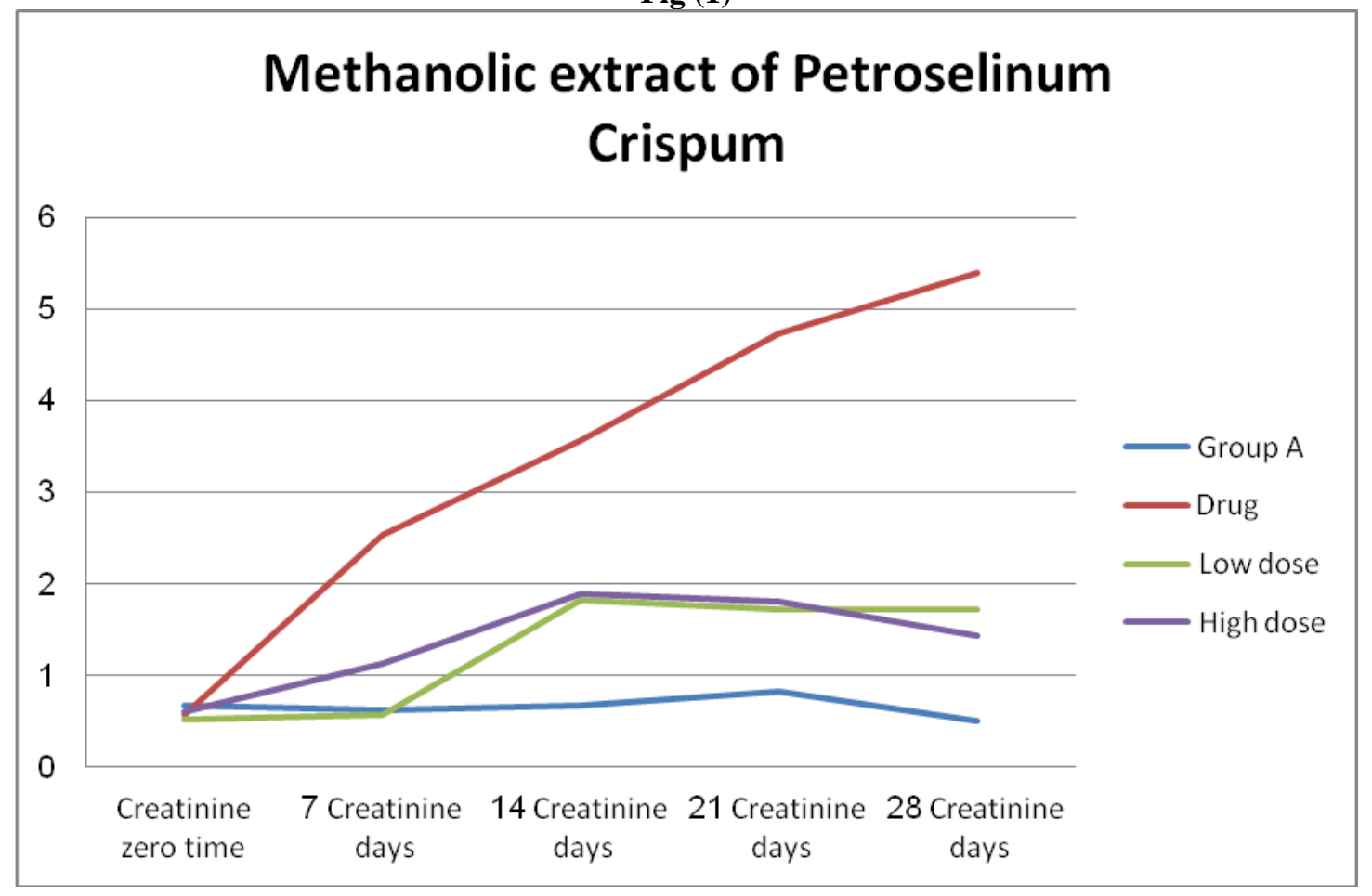


$\operatorname{Fig}(2)$

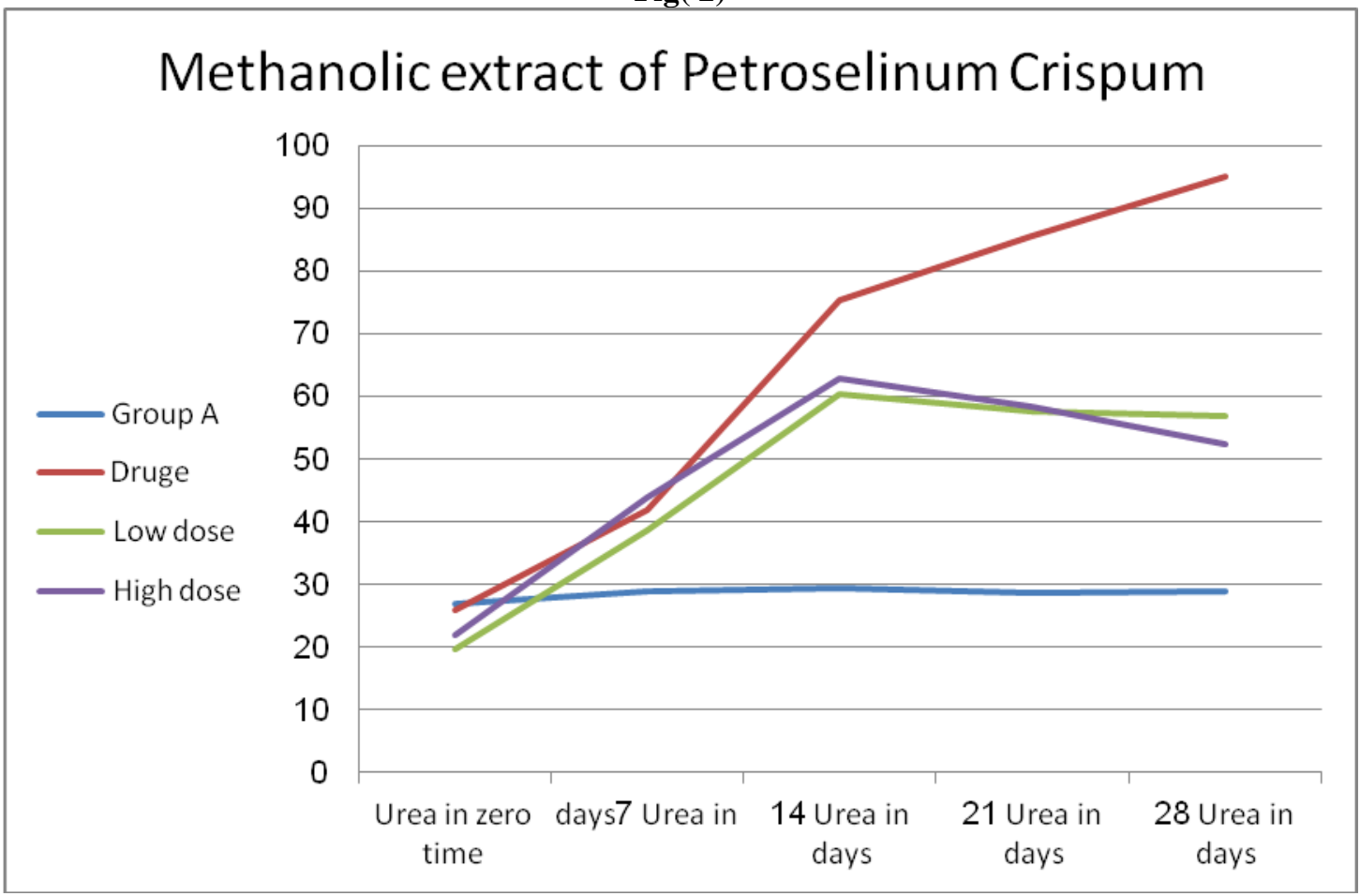

$\operatorname{Fig}(3)$

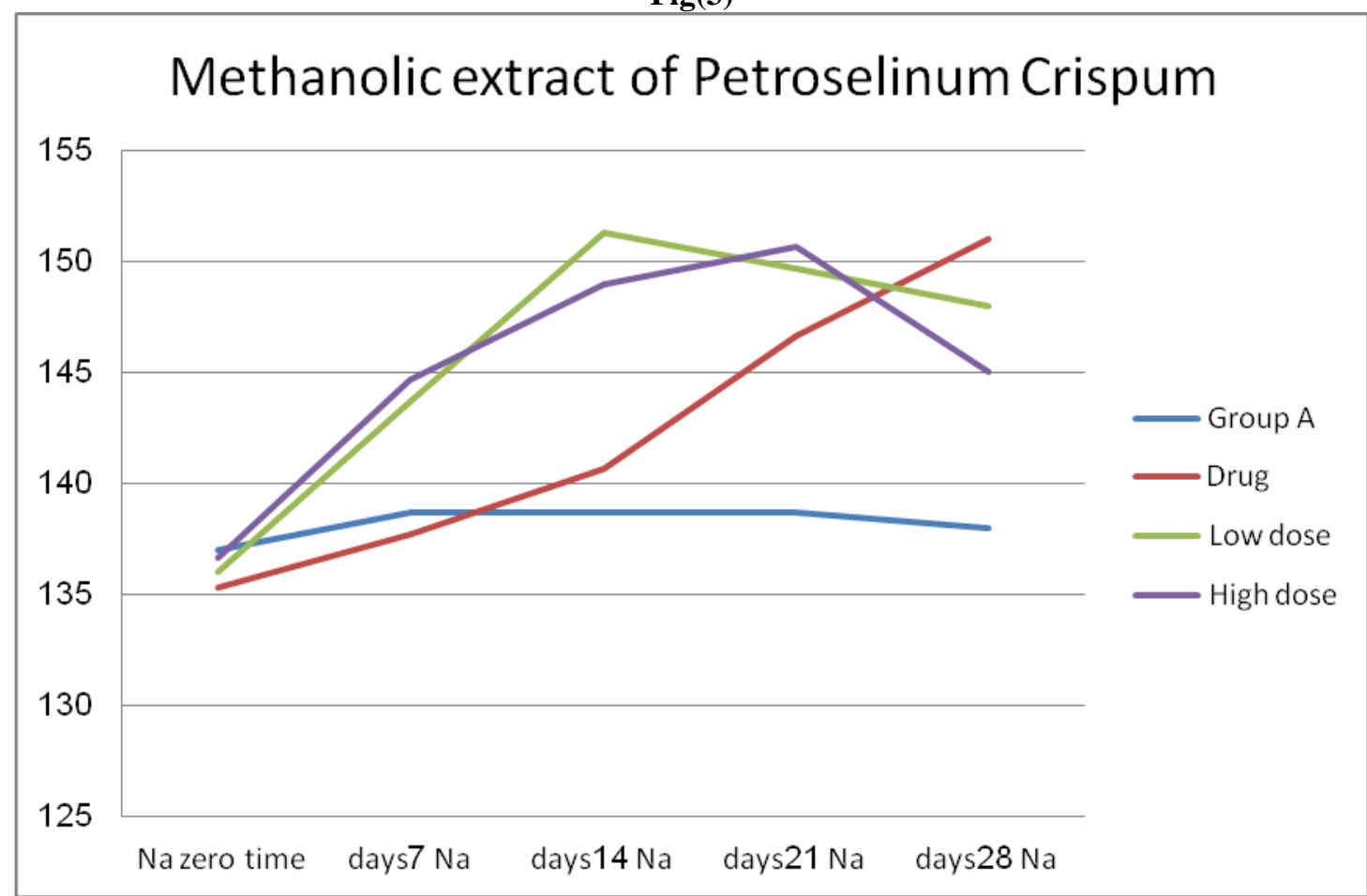


Fig( 4)

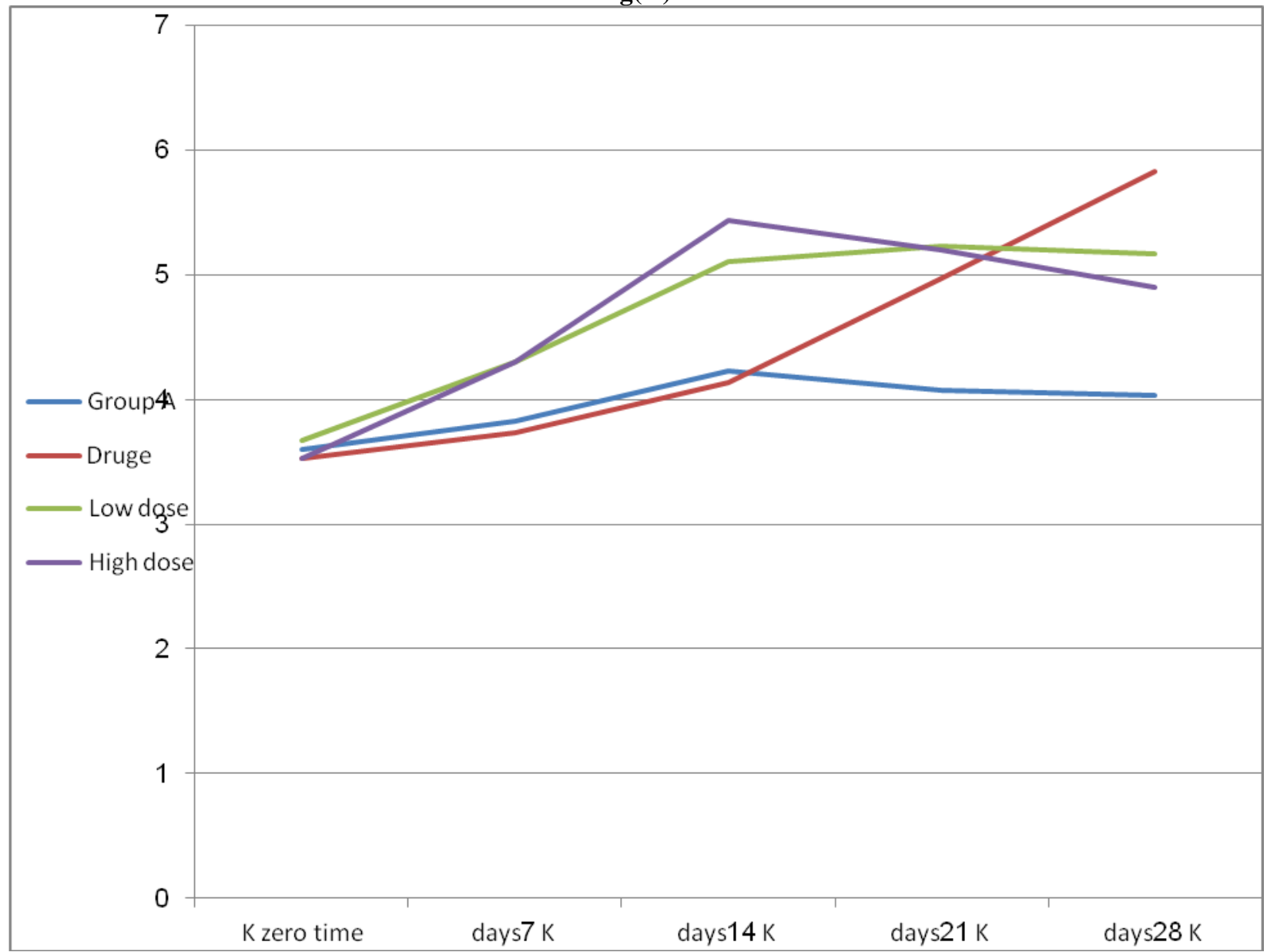

Table (1):

\begin{tabular}{|l|l|l|l|l|l|}
\hline Groups & $\begin{array}{l}\text { Urea in zero } \\
\text { time }\end{array}$ & $\begin{array}{l}\text { Urea in 7 } \\
\text { days }\end{array}$ & $\begin{array}{l}\text { Urea in 14 } \\
\text { days }\end{array}$ & $\begin{array}{l}\text { Urea in 21 } \\
\text { days }\end{array}$ & $\begin{array}{l}\text { Urea in 28 } \\
\text { days }\end{array}$ \\
\hline GroupA & $27.00 \pm 2.08$ & $29.01 \pm 6.11$ & $29.33 \pm 6.36$ & $28.67 \pm 5.81$ & $29.00 \pm 3.46$ \\
\hline Drug & $26.00 \pm 2.08$ & $42.00 \pm 6.11$ & $75.33 \pm 6.36$ & $85.67 \pm 5.81$ & $95.00 \pm 3.46^{*}$ \\
\hline Low dose & $19.67 \pm 1.20$ & $38.67 \pm 2.33$ & $60.33 \pm 3.18$ & $57.67 \pm 1.45^{*}$ & $57.00 \pm 1.53$ \\
\hline High dose & $22.00 \pm 3.06$ & $44.00 \pm 3.06$ & $63.00 \pm 2.08$ & $58.33 \pm .88$ & $52.33 \pm .88$ \\
\hline
\end{tabular}

Table (2)

\begin{tabular}{|l|l|l|l|l|l|}
\hline Groups & $\begin{array}{l}\text { Creatinine } \\
\text { zero time }\end{array}$ & $\begin{array}{l}\text { Creatinine } \\
7 \text { days }\end{array}$ & $\begin{array}{l}\text { Creatinine } \\
14 \text { days }\end{array}$ & $\begin{array}{l}\text { Creatinine } \\
21 \text { days }\end{array}$ & $\begin{array}{l}\text { Creatinine } \\
28 \text { days }\end{array}$ \\
\hline Group A & $.67 \pm .07$ & $.63 \pm .42$ & $.67 \pm .38$ & $.83 \pm .17$ & $.50 \pm .32$ \\
\hline Drug & $.57 \pm .07$ & $2.53 \pm .42$ & $3.57 \pm .38$ & $4.73 \pm .17$ & $5.40 \pm .32^{*}$ \\
\hline Low dose & $.53 \pm .03$ & $.57 \pm .03$ & $1.83 \pm .15$ & $1.73 \pm .07$ & $1.73 \pm .07^{*}$ \\
\hline High dose & $.60 \pm .06$ & $1.13 \pm .12$ & $1.90 \pm .17^{*}$ & $1.80 \pm .10$ & $1.43 \pm .03$ \\
\hline
\end{tabular}

Table (3):

\begin{tabular}{|l|l|l|l|l|l|}
\hline Groups & Na zero time & Na 7 days & Na 14 days & Na 21 days & Na 28 days \\
\hline Group A & $137.00 \pm .58$ & $138.67 \pm 1.20$ & $138.67 \pm 1.76$ & $138.67 \pm 2.85$ & $138.00 \pm 1.15$ \\
\hline Drug & $135.33 \pm .33$ & $137.67 \pm 1.20$ & $140.67 \pm 1.76$ & $146.67 \pm 2.85$ & $151.00 \pm 1.15^{*}$ \\
\hline Low dose & $136.00 \pm 1.53$ & $143.67 \pm .33$ & $151.33 \pm 2.03$ & $149.67 \pm .88$ & $148.00 \pm 1.53^{*}$ \\
\hline High dose & $136.67 \pm .88$ & $144.67 \pm 1.45$ & $149.00 \pm 2.08$ & $150.67 \pm .88^{*}$ & $145.00 \pm .00$ \\
\hline
\end{tabular}


Table (4):

\begin{tabular}{|l|l|l|l|l|l|}
\hline Groups & K zero time & K 7 days & K 14 days & K 21 days & K 28 days \\
\hline Group A & $3.60 \pm .12$ & $3.83 \pm .03$ & $4.23 \pm .09$ & $4.07 \pm .09$ & $4.03 \pm .09$ \\
\hline Drug & $3.53 \pm .09$ & $3.73 \pm .03$ & $4.13 \pm .09$ & $4.97 \pm .09$ & $5.83 \pm .09^{*}$ \\
\hline Low dose & $3.67 \pm .12$ & $4.30 \pm .15$ & $5.10 \pm .21$ & $5.23 \pm .13$ & $5.17 \pm .12^{*}$ \\
\hline High dose & $3.53 \pm .09$ & $4.30 \pm .21$ & $5.43 \pm .23$ & $5.20 \pm .12$ & $4.90 \pm .06^{*}$ \\
\hline
\end{tabular}

\section{Histopathological examination:-}

Histological examination of kidneys of normal rats showed normal histological structure of renal glomeruli and tubules (Fig.5A). Kidney of rats intoxicated with rifampin $(70 \mathrm{mg} / \mathrm{kg}$ ) for 28 days revealed marked tubular necrosis (Fig.5B) Kidneys of GM - nephrotoxic rats received the low dose $(300 \mathrm{mg} / \mathrm{kg})$ of parsley leaves extract showed large vaculations and peritubular leukocytes infiltration (Fig.5 C). Kidneys of nephrotoxic rats pre-treated orally with the large dose $(600 \mathrm{mg} / \mathrm{kg})$ of parsley leaves extract showed almost normal histological architecture of renal glomeruli and tubules (Fig.5D).

Fig. (5)

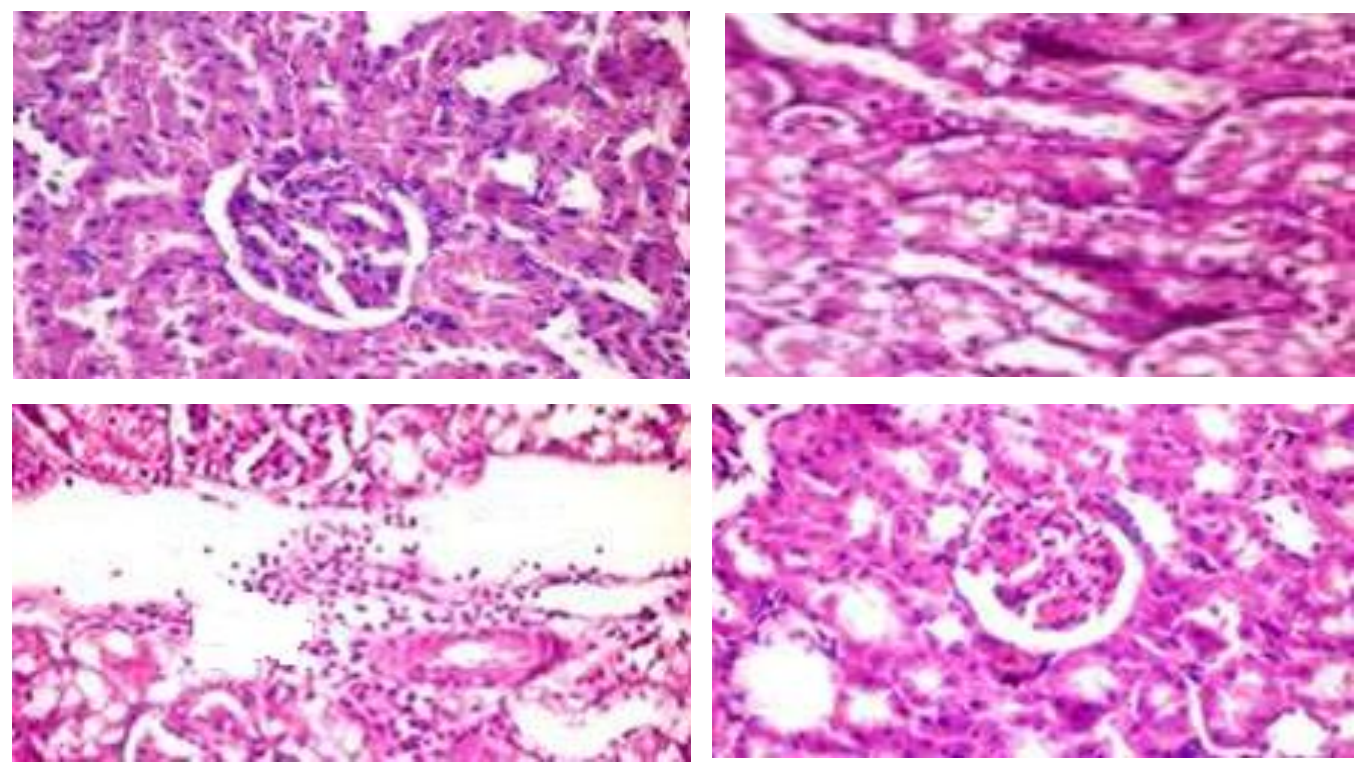




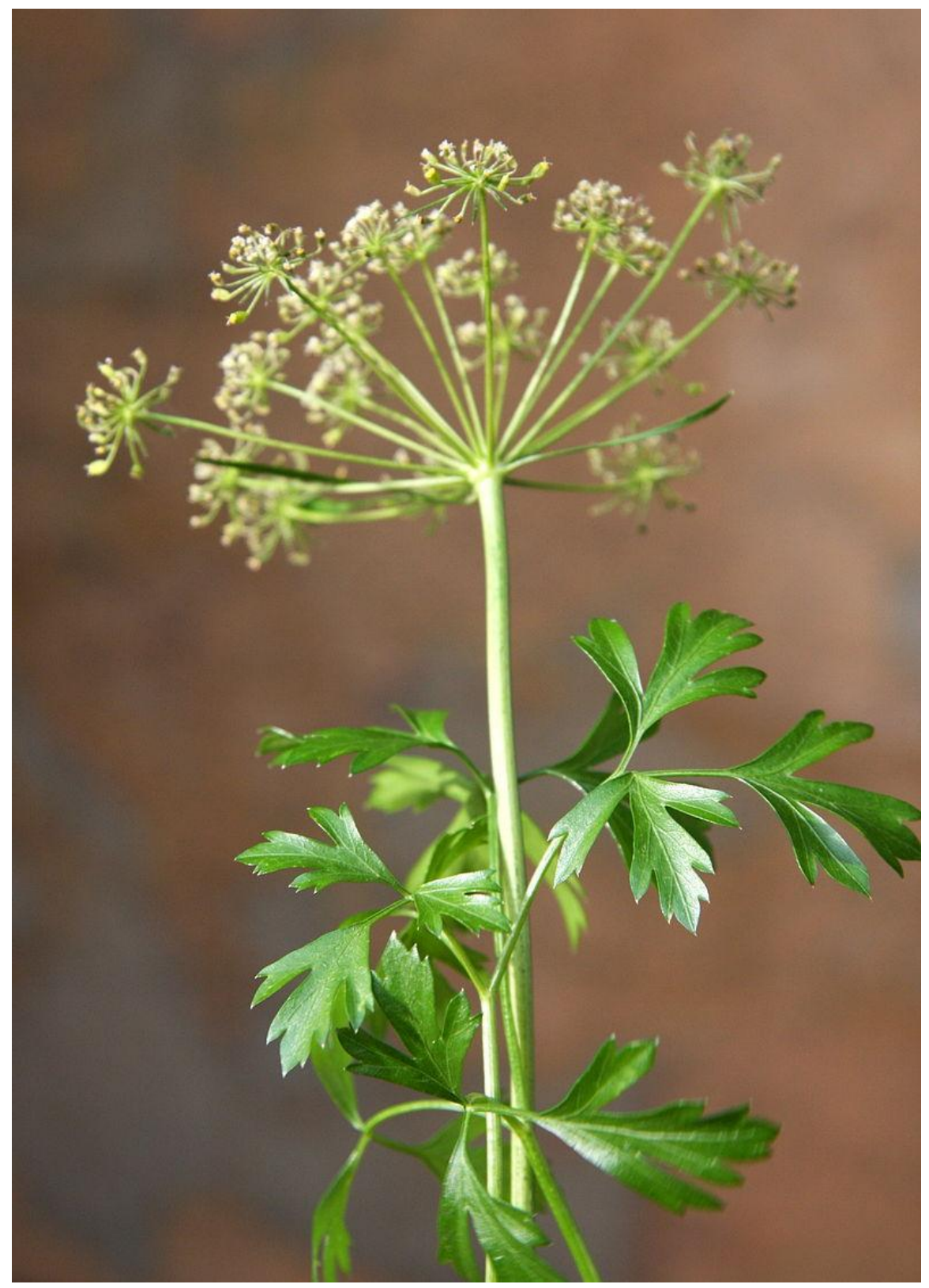

\section{Reference:-}

1. KDIGO: Kidney Disease Improving Global Outcomes (August 2009). "KDIGO Clinical Practice Guideline for sKidney Disease-Mineral and Bone Disorder (CKD-MBD)"(PDF). Kidney Int76 (Suppl 113).

2. Eknoyan G, Lameire N, Barsoum R (2004)."The burden of kidney disease: improving global outcomes". Kidney Int66: 1310-4. Doi: 10.1111/j.1523-1755.2004.00894.x. PMID 15458424.

3. Martínez A, Castelao; JL.Górriz; J Bover (2014)."Consensus document for the detection and management of chronic kidney disease".Nefrologia 34(2) : 243-262

4. National Kidney Foundation (2002)."K/DOQI clinical practice guidelines for chronic kidney disease".Retrieved 2008-06-29.

5. Bhawna, S., Kumar, S. U(2009) . Hepatoprotective activity of some indigenous plants. Int J Pharm Tech 1: 1330-1334.

6. Ogbera, A.O., Dada, O., Adeyeye, F(2010) . Complementary and alternative medicine use in diabetes mellitus. West Afr J Med 29(3): 158-162. 
7. Morales, A. I., Vicente-Sánchez, C., Sandoval, J. M (2006) . Protective effect of quercetin on experimental chronic cadmium nephrotoxicity in rats is based on its antioxidant properties. Food ChemToxicol 44(12): 20922100 .

8. Abdelaal, A., El-Ghaffar, H.A., Hosam, M (2009). Genotypic detection of rifampicin and isoniazid resistant Mycobacterium tuberculosis strains by DNA sequencing: a randomized trial. Ann ClinMicrobiolAntimicrob 8: 4.

9. Tostmann, A., Boeree, M. J., Aarnouts, R. E(2008) . Antituberculosis drug - induced hepatotoxicity. J GastroenterolHepatol 23: 192-202.

10. Kumar, R., Bhatia, V., Khanal, S., et al. Antituberculosis therapy-induced acute liver failure: magnitude, profile, prognosis, and predictors of outcome. (2010) Hepatology 51: 1665-1674.

11. Mahmoud, A.M., Germoush M. O., Soliman. A.S (2014) . Berberine attenuates isoniazid-induced hepatotoxicity by modulating peroxisome proliferator-activated receptor $\gamma$, oxidative stress and inflammation. Int J Pharmacol 10: 451-460.

12. Pal, R., Vaiphei, K., Sikander, A(2006) . Effect of garlic on isoniazid and rifampicin - induced hepatic injury in rats. World J Gastroenterol 12: 636-639.

13. Lopez-Novoa, J. M., Quiros, Y., Vicente, L(2011). New insights into the mechanism of aminoglycoside nephrotoxicity: an integrative point of view. Kidney Int 79: 33-45.

14. Parsley. Review of Natural Products.factsandcomparisons4.0 [online]. 2004. Available from Wolters Kluwer Health, Inc. Accessed April 19, 2007.

15. Adebisi, S. A., Oluboyo, P. O., Okesina, A. B (2000) . Effect of drug-induced hyperuricaemia on renal function in Nigerians with pulmonary tuberculosis. Afr J Med MedSci29 (3-4):297-300.

16. Adeneye, A.A., Benebo, A.S. Protective effect of the aqueous leaf and seed extract of Phyllanthusamarus on gentamicin and acetaminophen-induced nephrotoxic rats. (2008) J Ethnopharmacol 118(2): 318-323.

17. Hashmi, N., Muhammad, F., Javed, I (2013). Nephroprotective effects of Ficusreligiosalinn (peepals plant) stem bark against isoniazid and rifampicin induced nephrotoxicity in albino rabbits. Pak Vet J 33(3): 330-334. 